2 竎

\section{Operating Modes of the SSC Sector Station Cryogenic System}

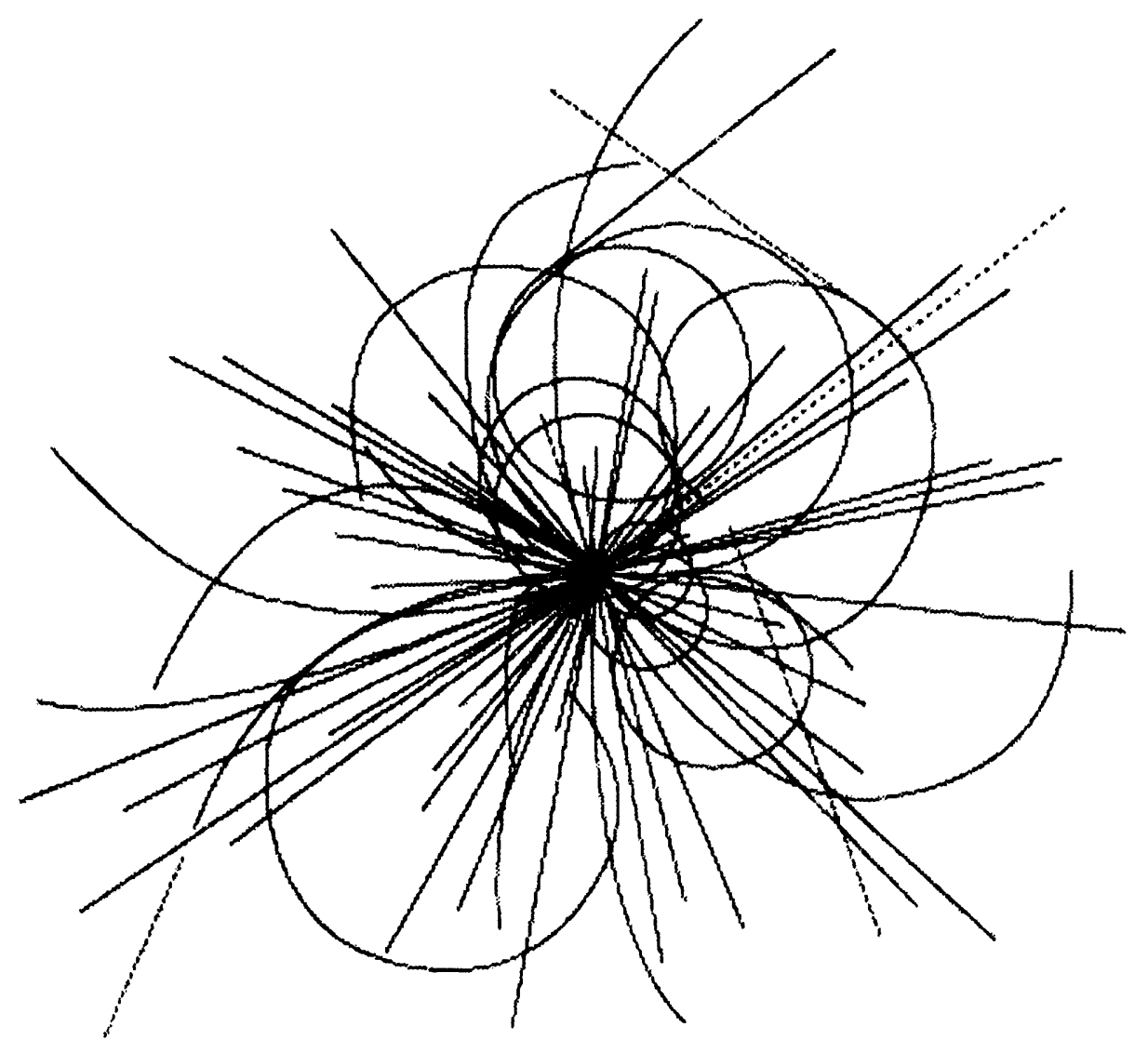

\section{Superconducting Super Collider Laboratory}

SSCL-Preprint-297

May 1993

Distribution Category: $\mathbf{4 1 4}$

V. Ganni

S. Abramovich

T.V.V.R. Apparao

$$
\begin{array}{r}
111+3 \\
-391
\end{array}
$$




\section{Disclaimer Notice}

This report was prepared as an account of work sponsored by an soency of the United Slates Government. Neither the United States Government of any agency thereof, nor any of their employees, makes any warranty, express or implied, of assumes any legal liability or responsibility for the accuracy, completeness, or usefuiness of any information, apparatus, product, or process disclosed, or represents that its use would not infringe privately owned rights. Referer.ce herein to any specitic commercial product, process, or service by trade name, trademark, manufacturer, or otherwise, does not necessarily constitute or imply its endorsement, recommendation, or favoring by the United States Government or any agency thereot. The views and opinions of authors expressed herein do not necessarily state or reflect those of the United States Govemment or any agency thereot.

Superconducting Super Collider Laboratory is an equal opportunity employer. 


\title{
Operating Modes of the SSC Sector Station Cryogenic System*
}

\author{
V. Ganni, S. Abramovich, and T.V.V.R. Apparao \\ Superconducting Super Collider Laboratory ${ }^{\dagger}$ \\ 2550 Beckleymeade Ave. \\ Dallas, TX 75237
}

May 1993

\footnotetext{
"Presented at the Fifth Annual International Symposium on the Super Collider, May 6-8, 1993 San Francisco, CA. 'Operated by the Universities Research Association, Inc., for the U.S. Department of Energy under Contract No. DE-AC35-89ER40486.
}

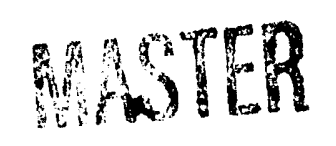




\title{
OPERATING MODES OF THE SSC SECTOR STATION CRYOGENIC SYSTEM
}

\author{
V. Ganni, S. Abramovich, and T. V. V. R. Apparao \\ SSC Laboratory, ${ }^{*}$ ASD, Cryogenics Department, Dallas, TX 75237-3997
}

\section{INTRODUCTION}

The magnets in the Collider rings and in the HEB (High Energy Booster) ring are refrigerated by single phase helium flow controlled at a temperature of $4 \mathrm{~K}$ to maintain the magnet windings in the superconductive state. To minimize the heat load into the $4 \mathrm{~K}$ loop, the magnet cryostats are designed to provide high quality thermal insulation achieved by a high vacuum with multilayer insulation (MLI) and by two thermal shields at a nominal temperatures of $84 \mathrm{~K}$ and $20 \mathrm{~K}$. respectively.

An extensive cryogenic system capable of normal operation of the superconducting magnets and handling transient conditions such as quenches, beam activation, ring filling, and beam ramping is required. The cryogenic system must also have the capability to perform other services such as cleanup, cooldown, and warmup, to allow for maintenance and repair of the superconductive components throughout the ring.

The refrigeration system is designed with a specific capacity to meet each of the various loads viz. $4 \mathrm{~K}$ refrigeration, $4 \mathrm{~K}$ liquefaction and $20 \mathrm{~K}$ shield cooling, to meet all the loads during normal and upset conditions and possess some extra capacity. The static heat leak and dynamic load to the $4 \mathrm{~K}$ components are the $4 \mathrm{~K}$ refrigeration load. It is handled by the latent heat of vaporization in the helium recoolers. The $4 \mathrm{~K}$ helium used for cooling the electrical leads returned at $300 \mathrm{~K}$ to the refrigerator, is the liquefaction load. The 20 $\mathrm{K}$ shield that absorbs part of the radiation and the static heat leak above $20 \mathrm{~K}$ is the $20 \mathrm{~K}$ refrigeration load. This load is handled by supplying $200 \mathrm{~g} / \mathrm{s}, 3.0 \mathrm{bar}$ helium at $14 \mathrm{~K}$ and returns the helium to the refrigerator at a temperature depending on the load. The refrigeration system has one spare compressor. It is capable of delivering $4 \mathrm{~K}$ and $20 \mathrm{~K}$ refrigeration and part of the liquefaction load in the nominal mode of operation given in Table 1 even when any one of the expanders fail.

Figure (1) is a block diagram showing the major components and their relative locations in the Sector Station Cryogenics System (SCS) which are the Sector Refrigeration Surface System (SRS), Sector Refrigeration Tunnel System (SRT) and the Sector Refrigeration Control System (SRC). There are many operating modes for the SCS and for each mode of operation there is a different scheme for the cryogen flows. The SCS is reconfigured each time by switching and by activation/deactivation of specific sets of equipment that allow for adjusting the process conditions, capacity and the throughput. The line numbers shown in Figure $l$ as well as a detailed description of the plant operation is given in Reference. ${ }^{1}$

This paper summarizes the operating modes of the SCS, the various states and processes.

\section{THE OPERATING MODES OF THE SCS}

The various modes of operation are defined as follows: Design Mode. Nominal Mode, Standby Mode, Assist Mode, and Utility Modes. Figure 2 shows the various system states and plant operational modes.

The refrigeration capacity required for a sector in four different modes of operation is given in Table 1. The design mode loads have a design margin of $25 \%$ for the $4 \mathrm{~K}$ loads and $50 \%$ margin for the $20 \mathrm{~K}$ load compared to the nominal mode. These margins account for the variation in the loads from sector to sector due to the difference in the lengths of the actual sectors and provide extra capacity required in the Assist Mode. The SCS is operated in the Nominal Mode when the collider is at full normal operation. This means the system is cold and the beam is on. The dynamic heat load on the system depends on the beam intensity. The $20 \mathrm{~K}$ shield cooling load remains unchanged in the Nominal. Standby and Assist modes of operation. The heat load budgets for each individual sector in the collider as well as the HEB sectors are given in Reference. ${ }^{1}$

The SCS is operated in the Standby Mode when the collider is cold at nominal temperatures, with no beam operating. Hence the refrigeration and liquefaction loads are lower than in the nominal mode. In this mode of operation the refrigeration load depends only on the "static load." The liquefaction load used for the electrical leads may be reduced since there is no electrical current. The excess liquid produced in the assist mode is transferred to a neighboring sector where the refrigeration plant is operating below nominal capacity. 
During a quench, a large amount of energy $(\sim 7 \mathrm{MJ})$ is transformed into heat and deposited in the cold mass. The magnets are protected by quickly aborting the beam and ramping down the electric cirren. The quench valves are opened and helium is vented from the cold mass into the $20 \mathrm{~K}$ line. The cold inass is then gradually brought back to nominal operating temperature. Operations such as cleanup, cooldown, warmup and maintenance are part of utility mode operations. The heat capacity of a sector is highly dependent on the temperature. The process times for each of these utility modes depends on the temperature level and the changes in the fluid inventory. Table 2 shows the fluid inventory in each of the cryogenic lines and the process times for each of the utility mode operations in a sector.

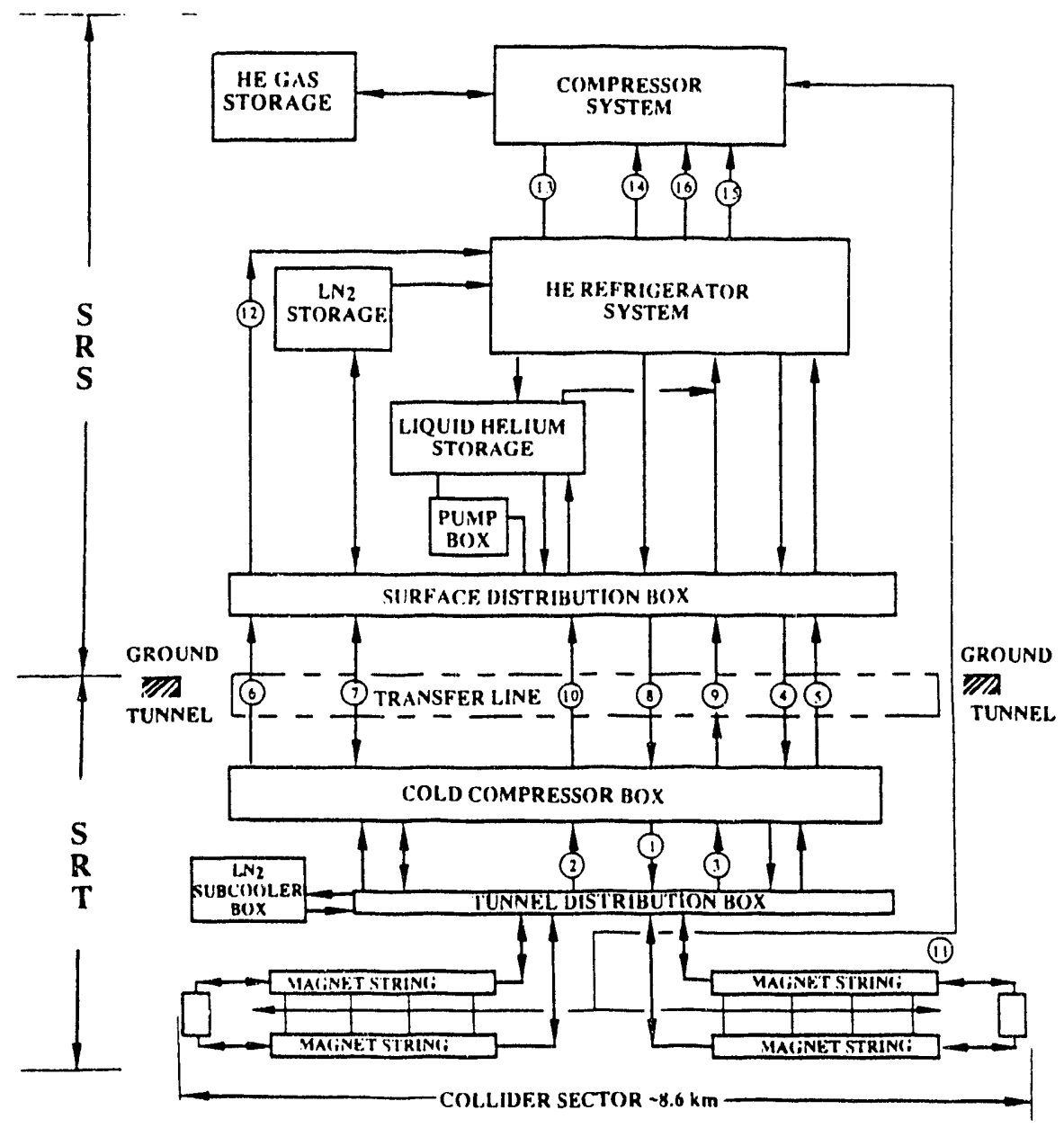

Figure 1. Sector Station Cryogenic System Block Diagram.

Table 1. SCS Capacity for Different Modes of Operation.

\begin{tabular}{|c|c|c|c|c|c|c|c|c|c|c|c|c|c|c|}
\hline & \multicolumn{6}{|c|}{ DESIGN MODE } & & \multicolumn{3}{|c|}{ NOMINAL } & \multicolumn{3}{|c|}{ MODE } & \multirow[b]{2}{*}{ W(Car } \\
\hline & PI & $\mathrm{TI}$ & PO & TO & Flow & Load! & $W(\mathrm{Car})$ & PI & $\mathrm{TI}$ & $\mathrm{PO}$ & TO & Fluw & Loat & \\
\hline & $\mathrm{MPa} !$ & $\mathrm{K}$ & $\mathrm{MPa}$ & $\mathrm{K}$ & $\mathrm{g} / \mathrm{s}$ & Watts & $\mathrm{KW}$ & $\mathrm{MPa}$ & $\mathrm{K}$ & $\mathrm{MPa}$ & $\mathrm{K}$ & $\mathrm{g} / \mathrm{s}$ & Watk & $\mathrm{KW}$ \\
\hline Refrigeration & 0.400 & 4.0 & 0.077 & 3.95 & 330 & 6750 & 574 & $0.4(x)$ & 4.0 & 0.077 & 3.95 & 264 & 5400 & 461 \\
\hline Liquefaction & 0.400 & 4.0 & 1.05 & 305 & 45 & & 320 & 0.400 & +0 & 1.05 & 305 & 36 & & 256 \\
\hline $20 \mathrm{~K}$ system & 0.400 & 14.0 & 0.2 & 27.8 & 200 & 15000 & 302 & $0.300)$ & $1+.0$ & 0.2 & 23.2 & 200 & $10003 ?$ & 208 \\
\hline Cold Compressor & 0.075 & 4.3 & 0.145 & 6.07 & 330 & $27+5$ & 48 & 0.075 & 4.3 & 0.14 & 6.06 & 264 & 2235 & 45 \\
\hline \multirow[t]{2}{*}{ Total Capacity } & & & & & & & 1244 & & & & & & & 970 \\
\hline & \multicolumn{3}{|c|}{ STANDBY } & \multicolumn{2}{|c|}{ MODE } & & & \multicolumn{3}{|c|}{ ASSIST } & \multicolumn{2}{|c|}{ MODE } & & \\
\hline Refrigeration & 0.400 & 4.) & 0.077 & 3.195 & 138 & 2800 & 238 & 0.400 & 4.0 & 0.077 & 3.95 & 264 & 5400 & 461 \\
\hline Liquefaction & 0.400 & +0 & 1.05 & 305 & 25 & & 178 & $0 .+(0)$ & +0 & 1.05 & 305 & 54 & & 384 \\
\hline $20 \mathrm{~K}$ system & $0.3(0)$ & 14.0 & 0.2 & 27.8 & $2(x)$ & $10(1)(x)$ & 2018 & 0.300 & $1+.0$ & 0.2 & 23.2 & 200 & 10000 & 208 \\
\hline Cold Compressor & 0.075 & +3 & 01.135 & 6.115 & 1.38 & 1191 & 27 & 0.1775 & +3 & 01.14 & 6.106 & 264 & 2235 & 45 \\
\hline Total Capacity & & & & & & & 651 & & & & & & & 1098 \\
\hline
\end{tabular}


The plant is operated in special modes for other types of collider configurations such as single ring cryogenic operation. The plant is said to operate in maximum capacity mode when the sector loads are high, or when assisting a neighboring sector, or when handling additional liquefaction load. It is operated in minimum capacity mode when the sector heat loads are low such as in a standby condition of the ring.

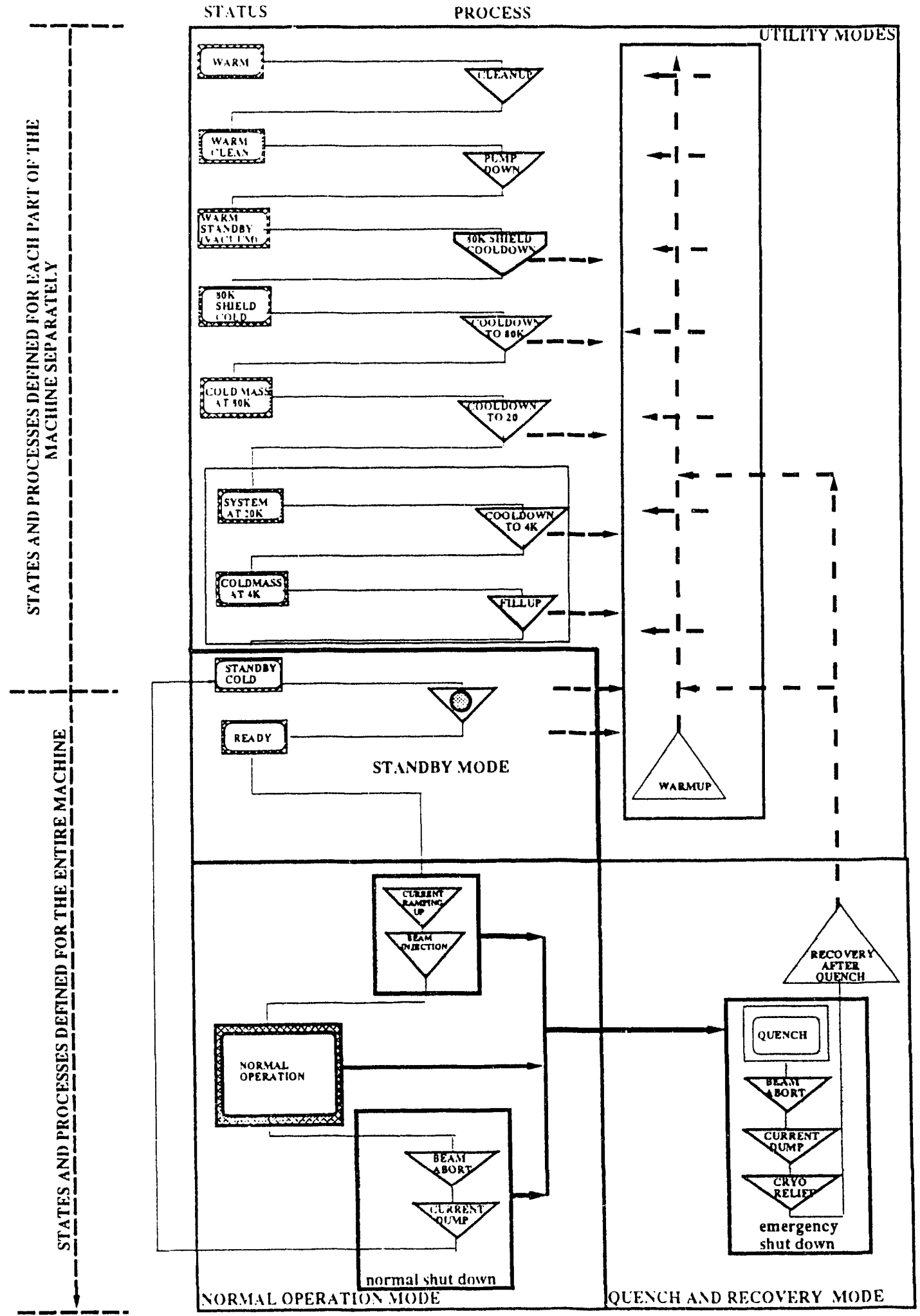

Figure 2. The System States and the Operational Modes. 


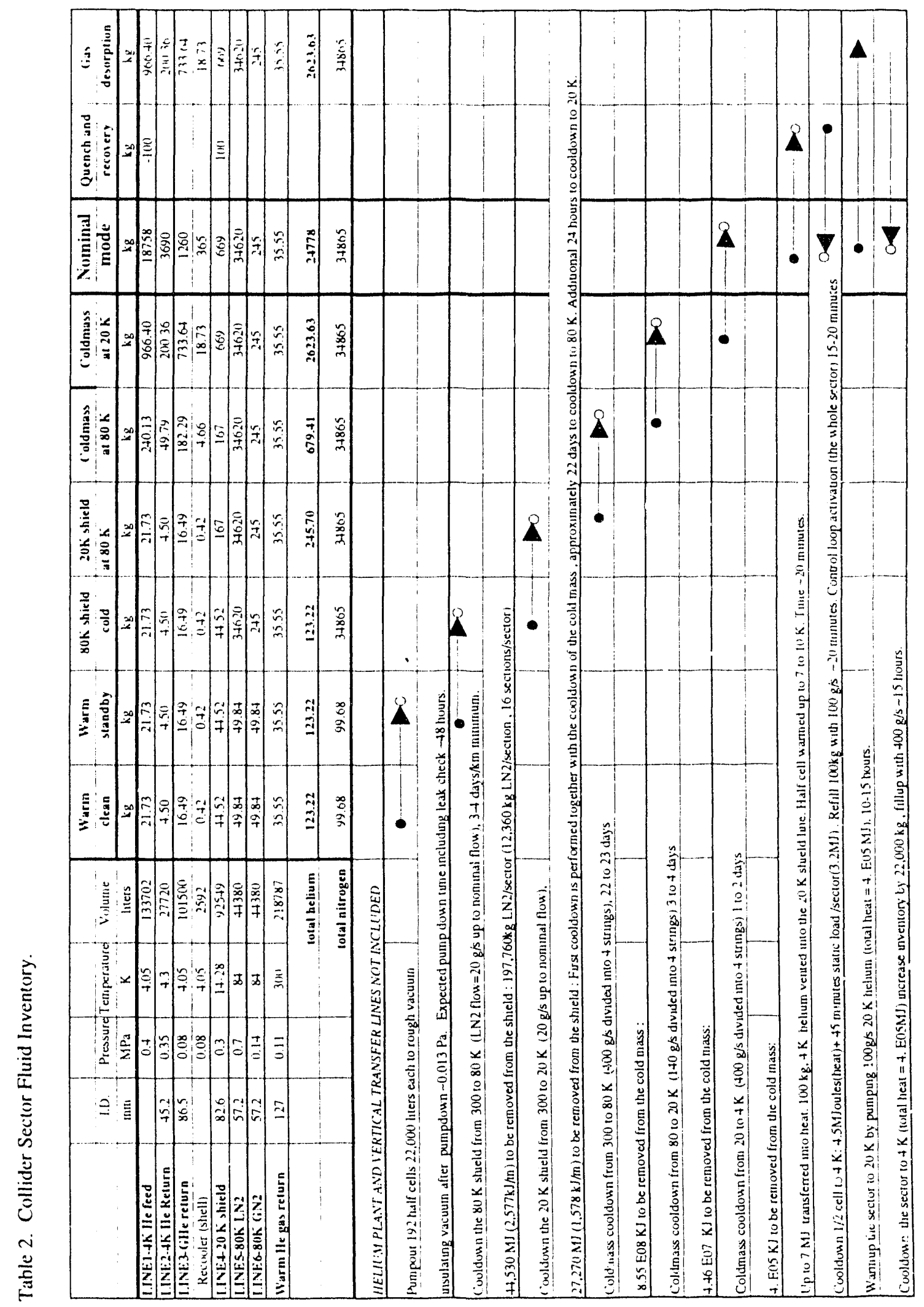

\section{REFERENCES}

1. R. Than. S. Abramovich. V. Ganni. "The SSC Cryogenic System Design and Operating Modes."

* Operated by the Universities Research Association, Inc., for the L. S. Department of Energy under Contract No. DE-AC35-89ER+0486. 

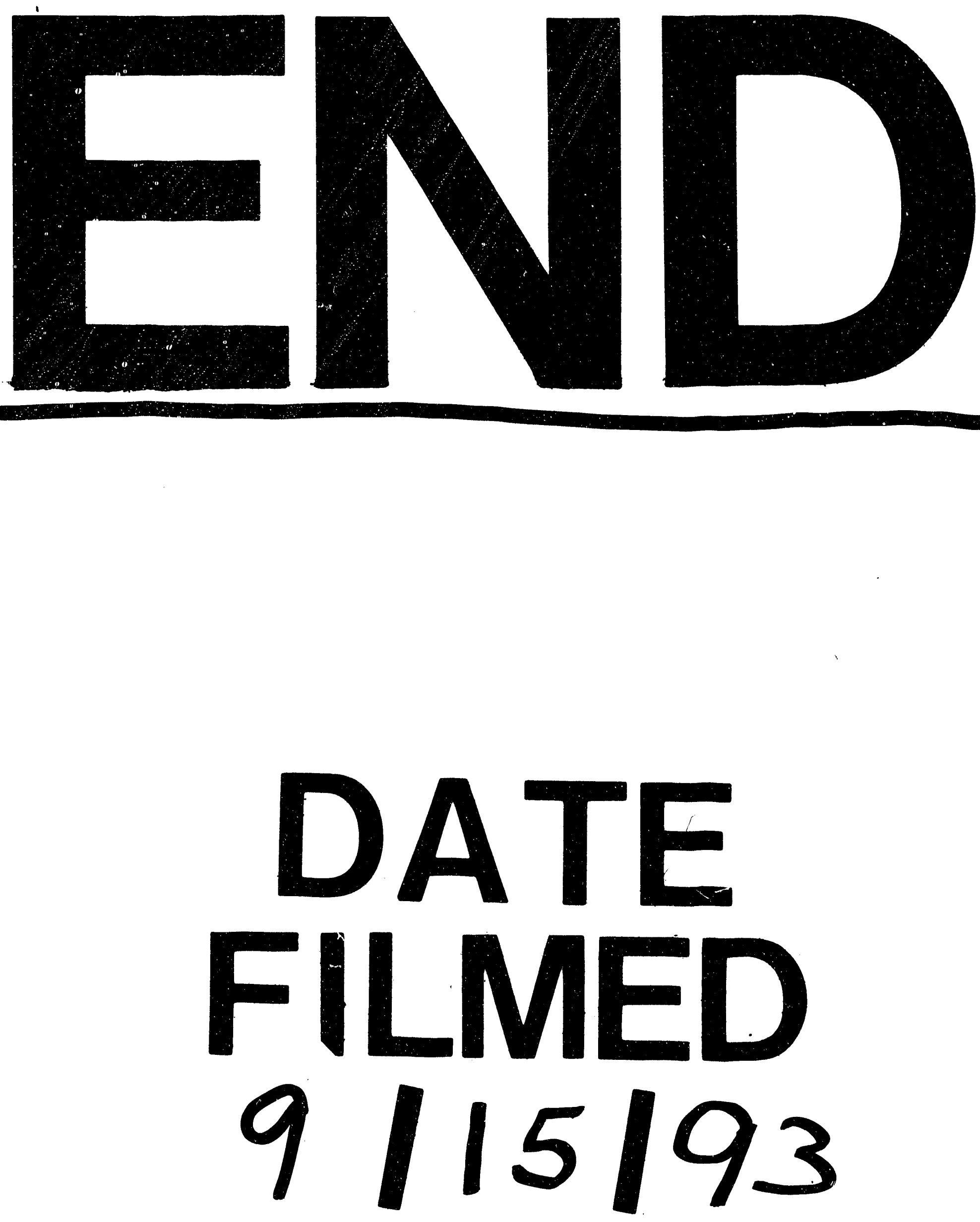

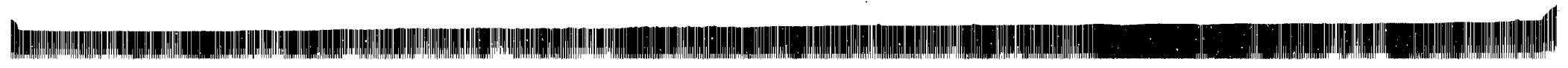


